\title{
PERANCANGAN PROTOTIPE PENDETEKSI KERUSAKAN POMPA AIR PADA SISTEM PENGISIAN AIR OTOMATIS MENGGUNAKAN FLOWMETER DAN MEMANFAATKAN SIM800L SEBAGAI PEMBERI NOTIFIKASI SMS BERBASIS ARDUINO MEGA 2560
}

\author{
${ }^{1)}$ Dyan Prabowo, ${ }^{2)}$ Wisnu Djatmiko \\ ${ }^{I}$ Mahasiswa Prodi Pendidikan Teknik Elektronika Fakultas Teknik Universitas Negeri Jakarta \\ ${ }^{2,3}$ Dosen Prodi Pendidikan Teknik Elektronika Fakultas Teknik Universitas Negeri Jakarta \\ Email: ${ }^{1)}$ dyanprabowo@gmail.com ${ }^{2}{ }^{w}$ wisnu.dj@unj.ac.id
}

\begin{abstract}
ABSTRAK
Abstrak- Perancangan Prototipe Pendeteksi Kerusakan Pompa Air Pada Sistem Pengisian Air Otomatis Menggunakan Flowmeter dan Memanfaatkan SIM800L Sebagai Pemberi Notifikasi SMS Berbasis Arduino Mega 2560. Komprehensif. Jakarta: Program Studi Pendidikan Teknik Elektronika, Fakultas Teknik, Universitas Negeri Jakarta, 2017. Dosen Pembimbing, Wisnu Djatmiko. Tujuan penulisan komprehensif adalah merancang prototipe yang dapat mendeteksi kerusakan sistem distribusi pengisian air otomatis berdasarkan pembacaan debet aliran air, serta dapat mengirimkan informasi kerusakan melalui SMS. Prototipe pendeteksi kerusakan pengisian air otomatis yang dirancang terdiri dari 6 subsistem, antara lain; subsistem pembacaan ketinggian air dalam tangki menggunakan sensor water level, subsistem pengisian air menggunakan pompa secara otomatis, subsistem pembacaan debet pompa air menggunakan sensor flowmeter, subsistem pengirim notifikasi berupa SMS menggunakan SIM800L, subsistem tampilan informasi menggunakan LCD dan subsistem pengolah data menggunakan Arduino Mega 2560. Metode penelitian yang diterapkan adalah $R \& D$, namun hanya sampai tahap desain produk atau tanpa pengujian. Hasil Penulisan ini menunjukan perancangan prototipe pendeteksi kerusakan pengisian air otomatis menggunakan flowmeter dan memanfaatkan SIM800L sebagai pemberi notifikasi SMS berbasis arduino mega 2560 dalam bentuk diagram blok sistem dan flowchart.
\end{abstract}

Kata-kata Kunci : Pendeteksi kerusakan, Pengisian air, Sensor Flowmeter, SMS

Abstract- Designing a Water Pump Damage Detection Prototype in an Automatic Water Filling System Using a Flowmeter and Utilizing SIM800L as an Arduino Mega 2560 Based SMS Notification Giver. Comprehensive. Jakarta: Electronics Engineering Education Study Program, Faculty of Engineering, Jakarta State University, 2017. Advisor, Wisnu Djatmiko. The aim of comprehensive writing is to design a prototype that can detect damage to the automatic water filling distribution system based on the water flow debit reading, and can send damage information via SMS. The prototype for detecting automatic water filling damage which is designed consists of 6 subsystems, among others; the water level reading subsystem uses a water level sensor, the water filling subsystem uses a pump automatically, the water pump debit reading subsystem uses a flowmeter sensor, the notification sending subsystem uses the SIM800L, the information display subsystem uses an LCD and the data processing subsystem uses the Arduino Mega 2560. The research method applied is R\&D, but only up to the product design stage or without testing. The results of this writing show the design of an automatic water filling damage detection prototype using a flowmeter and utilizing the SIM800L as an arduino mega 2560 based SMS notification in the form of a system block diagram and flowchart.

Keywords: Damage detector, Water filling, Flowmeter sensor, SMS 


\section{PENDAhuluan}

Dalam merancang bangunan bertingkat bukan hanya keindahan tampak bangunan saja yang diperhatikan, bangunan juga harus memenuhi persyaratan teknis lainnya, seperti tata bangunan, lingkungan dan keandalan bangunan gedung (PERMENPU, 2006). Salah satu aspek yang harus dipenuhi berkaitan dengan persyaratan keandalan bangunan gedung adalah persyaratan sanitasi dimana kualitas air bersih, sistem distribusi dan penampungan air harus sesuai pedoman serta persyaratan teknis yang berlaku. Dari beberapa sistem berkaitan dengan distribusi air yang ada pada gedung biasanya yang memiliki tingkat kerusakan lebih sering adalah pada sistem distribusi penampungan air bersih, sebab dalam sistem ini terdapat beberapa tahapan yang seluruhnya bergantung pada pompa-pompa dengan jumlah durasi kerja yang cukup besar setiap harinya. Oleh karena itu, penulis bermaksud untuk membuat rancangan prototipe pendeteksi kerusakan pompa air pada pengisian air otomatis menggunakan sensor flowmeter dan memanfaatkan SIM800L sebagai pemberi notifikasi SMS berbasis Arduino Mega 2560.

\section{METODOLOGI PENELITIAN}

Menurut Sugiyono metode penelitian merupakan cara ilmiah untuk mendapatkan data dengan tujuan dan kegunaan tertentu (Sugiyono, 2013). Metode penelitian dapat diartikan sebagai suatu kegiatan ilmiah dalam memecahkan masalah dengan cara sistematis yang telah ditetapkan untuk mencapai tujuan yang telah dirumuskan. Jenis metode penelitian yang digunakan mengacu pada riset dan pengembangan atau R\&D (Research \& Development). Menurut Sugiyono langkahlangkah penelitian R\&D terdiri dari 10 langkah, yakni potensi masalah, pengumpulan data, desain produk, validasi desain, ujicoba pemakaian, revisi produk, ujicoba produk, revisi desain, revisi produk dan produksi masal (Sugiyono, 2009), secara skematik ditunjukan pada Gambar 3.1.

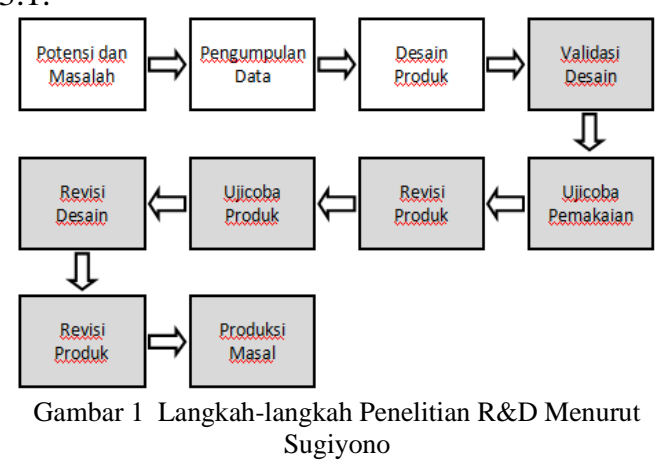

III. HASIL DAN PEMBAHASAN
Langkah-langkah penelitian yang diterapkan dalam penelitian ini tidak sampai tahap pengujian, atau hanya meliputi potensi dan masalah, pengumpulan data atau studi literatur dan desain produk atau perancangan.

\section{A. Analisis Kebutuhan Sistem}

Analisis kebutuhan sistem dalam penulisan ini meliputi penentuan rancangan diagram blok sistem dan kebutuhan komponen atau perangkat yang harus dipenuhi dalam merancang prototipe pendeteksi kerusakan sistem pengisian air otomatis sesuai dengan kriteria yang telah dirumuskan.

B. Menentukan Rancangan Diagram Blok Sistem

Dalam merancang sebuah sistem hal terpenting adalah menjadikan sistem menjadi tiga bagian besar, pertama input (masukan), proses dan output (keluaran). Rancangan sistem dalam bentuk diagram blok dapat dilihat pada Gambar 2.

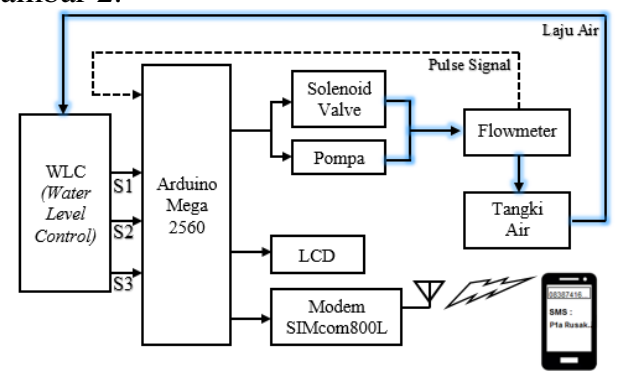

Gambar 2. Diagram Blok Sistem Prototipe Pendeteksi Kerusakan Pompa Air Pada Sistem Pengisian Air Otomatis

Berdasarkan blok diagram diatas yang menjadi bagian input adalah WLC (Water Level Control) dengan tiga indikator S1, S2 dan S3 serta signal pulsa yang dihasilkan flowmeter ketika dialiri air. Sedangkan outputnya adalah Pompa, solenoid valve yang dihubungkan paralel dengan pompa, LCD dan notifikasi berupa SMS yang dikirim melalui SIM800L.

WLC atau water level control berfungsi membaca level air pada tangki dan mengirim informasi ke Arduino Mega2560 untuk menentukan kapan pompa yang mengisinya harus aktif atau berhenti mengisi. Ketika WLC mendeteksi isi tangki air di bawah batas minimum, maka Arduino Mega2560 akan memberi perintah untuk mengaktifkan pompa untuk mengisi tangki. Flowmeter akan membaca debet air, kemudian mengirim informasi debet yang terbaca ke Arduino Mega2560. Apabila debet air yang terbaca flowmeter dibawah batas debet minimum yang ditentukan saat pompa aktif, maka pompa akan dinyatakan rusak dan SIM800L akan mengirim informasi kerusakan yang terdeteksi melalui pesan (SMS) ke nomor telepon yang akan ditentukan. 


\section{Perancangan Desain Maket}

Ilustrasi perancangan desain maket dapat dilihat pada Gambar 3.3.

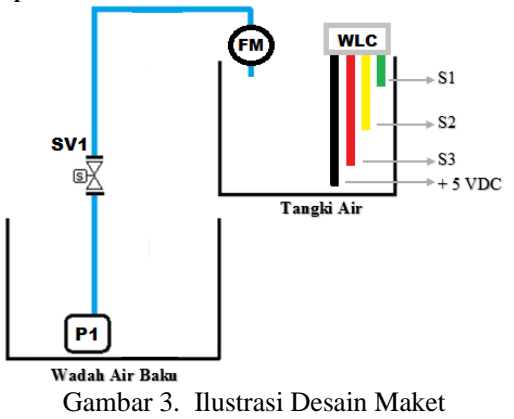

P1 adalah Pompa air, SV1 adalah Solenoid valve normally close yang dipasang pada output pompa air dan akan aktif ketika pompa air aktif (terhubung paralel), FM adalah Flowmeter G1/2 WLC adalah Water level control dengan S1 sebagai sensor atas, S2 Sensor tengah, S3 Sensor bawah sebagai batas minimum dan +5VDC tegangan yang dipancarkan untuk diterima sensor WLC melalui air

\section{Perancangan Penggunaan Port Arduino} Mega 2560

Pada tahap ini ditentukan inisialisasi pin arduino mega 2560 yang akan digunakan sebagai port input dan output sesuai dengan macammacam komponen yang sudah ditentukan. Daftar inisialisasi pin yang digunakan dapat dilihat pada Tabel 1. dan Tabel 2.

Tabel 1 Penggunaan Pin Arduino Mega2560 Untuk Perangkat Output

\begin{tabular}{|c|c|c|c|}
\hline No & \multicolumn{2}{|c|}{ Perangkat Output } & $\begin{array}{c}\text { Pin } \\
\text { Arduino }\end{array}$ \\
\hline 1 & Pompa & Driver & 3 \\
\hline 2 & Solenoid Valve & pompa & 3 \\
\hline \multirow{2}{*}{3} & \multirow{2}{*}{ SIMcom800L } & TXD & $0(\mathrm{Rx})$ \\
\cline { 3 - 4 } & RXD & $1(\mathrm{Tx})$ \\
\cline { 3 - 4 } & RESET & RESET \\
\hline \multirow{2}{*}{4} & $\begin{array}{c}\text { Modul LCD } \\
\text { Arduino 20x4 IIC }\end{array}$ & SDA & $\begin{array}{c}20 \\
\text { (SDA) }\end{array}$ \\
\cline { 3 - 4 } & & SCL & $\begin{array}{c}21 \\
\text { (SCL) }\end{array}$ \\
\hline
\end{tabular}

Tabel 2. Penggunaan Pin Arduino Mega2560 Untuk

\begin{tabular}{|c|c|c|c|}
\multicolumn{4}{|c|}{ Perangkat Input } \\
\hline \multirow{2}{*}{ No } & \multicolumn{2}{|c|}{ Perangkat Input } & $\begin{array}{c}\text { Pin } \\
\text { Arduino }\end{array}$ \\
\hline \multirow{2}{*}{1} & \multirow{2}{*}{ WLC } & S1 & A 0 \\
\cline { 3 - 4 } & & S2 & A1 \\
\cline { 3 - 4 } 2 & $\begin{array}{c}\text { Flowmeter } \\
\text { G1/2 }\end{array}$ & Pin signal & 2 (INT4) \\
\hline
\end{tabular}

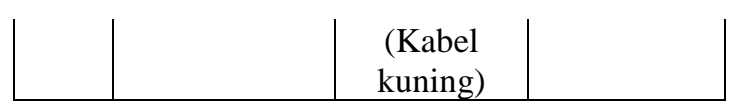

1) Pengintergrasian sensor WLC (water level control)

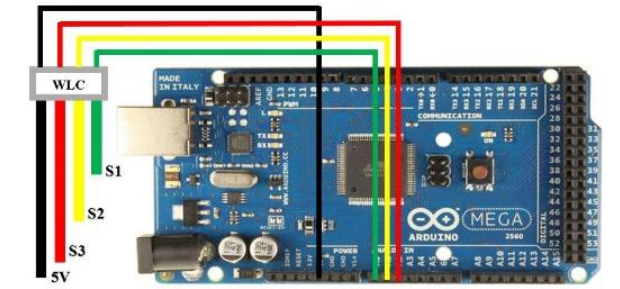

Gambar 2 Integrasi Sensor WLC dengan Arduino Mega 2560

Pada Gambar 4 adalah ilustrasi dari pengintegrasian sensor WLC ke arduino. Pin arduino yang digunakan untuk menerima signal dari sensor WLC adalah A0, A1 dan A2. Pin A0 dihubungkan dengan sensor $\mathrm{S} 1$, pin A1 dihubungkan dengan sensor S2 dan pin A2 dihubungkan dengan sensor S3.

2) Pengintegrasian pompa

Untuk menghubungkan pompa sebagai output dari arduino dibutuhkan rangkaian driver untuk merelay tegangan kerja pompa dan solenoid valve, karena tegangan kerja yang dibutuhkan adalah 220 Volt AC. Pin arduino yang digunakan untuk pompa adalah pin 3. Input tegangan 220 Volt AC untuk pompa dihubungkan paralel dengan solenoid valve. Skema rangkaian driver pompa tertera pada Gambar 3.5.

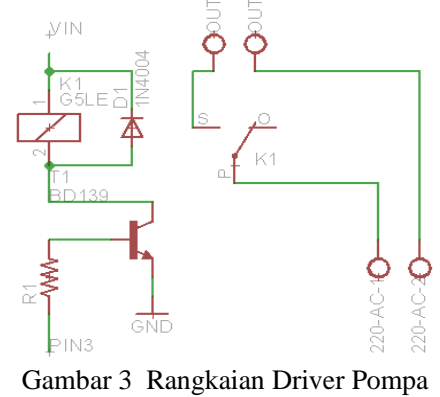

3) Pengintegrasian sensor water flowmeter G1/2

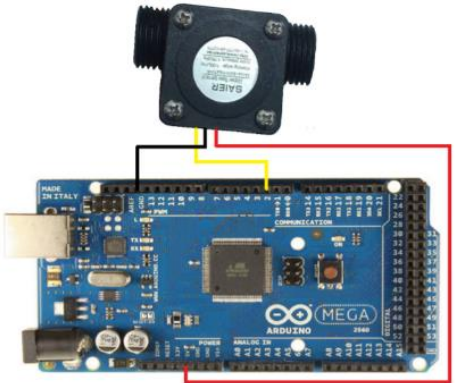

Gambar 4 Integrasi Sensor Flowmeter dengan Arduino Mega 2560 
Ilustrasi skema pengintegrasian flowmeter ke arduino ditunjukan pada Gambar 6. Kabel signal sensor flowmeter G1/2 dihubungkan ke pin 2 arduino mega 2560 (INT4). Dengan memanfaatkan fungsi interrupt untuk membaca sinyal pulsa yang dihasilkan flowmeter ketika dialiri air.

\section{4) Pengintegrasian SIM800L}

Modem SIM800L berkerja pada tegangan antara 3.4V dan 4.4V. Untuk itu diperlukan step down converter jika akan dihubungkan dengan VCC 5V arduino. Pada rancangan ini tegangan yang akan disesuaikan untuk SIM800L adalah $3,9 \mathrm{~V}$ dengan memanfaatkan VCC $5 \mathrm{~V}$ arduino. Tegangan diturunkan menjadi $3,9 \mathrm{~V}$ menggunakan dioda zener yang dipasang secara bias balik (reverse bias) sebagai step down converter. Skema pemanfaatan dioda zener secara bias balik dapat dilihat pada Gambar 7 .

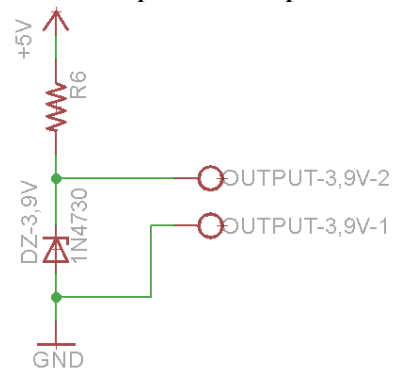

Gambar 5 Skema Bias Balik (Reverse Bias) Dioda Zener

Tegangan yang sudah diturunkan menjadi 3,9V dihubungkan ke VCC SIM800L. Pin arduino mega 2560 yang digunakan pin $0 \quad(\mathrm{Rx})$ dihubungkan ke TXD sedangkan pin 1 (Tx) ke RXD, kemudian RESET pada SIM800L dihubungkan ke pin RESET arduino. Ilustrasi pengintegrasian port SIM800L dapat dilihat pada Gambar 8 .

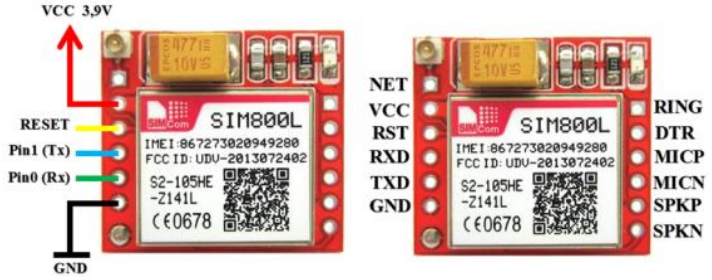

Gambar 6 Peta Port SIM800L dan Integrasi Port SIM800L dengan Pin Arduino

\section{5) Perancangan Integrasi Modul LCD Arduino} $20 \times 4$ IIC

Skema integrasi LCD dapat dilihat pada Gambar 3.9 .

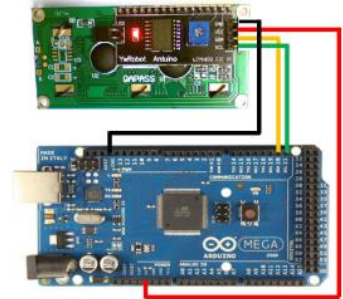

Gambar 7 Skema Integrasi LCD ke Arduino Mega 2560

Pin arduino yang digunakan adalah pin 20 (SDA) yang ditunjukan dengan garis warna kuning dan pin 21 (SCL) yang ditunjukkan dengan garis warna hijau.

E. Langkah Kerja Prototipe Pendeteksi Kerusakan Pompa Air Pada Sistem Pengisian Air Otomatis

Langkah-langkah kerja ketika sistem diaktifkan antara lain :

1) Sistem akan mengecek koneksi SIM800L, jika belum terbaca terkoneksi maka LCD akan menampilkan notifikasi bahwa SIM800L belum terkoneksi dan muncul perintah untuk cek dan restart.

2) Jika SIM800L terbaca sudah terkoneksi, maka pompa aktif untuk memastikan pompa dapat berfungsi, pengecekan menggunakan hasil pembacaan flowmeter pada keluaran pompa, apabila flowmeter tidak mendeteksi adanya aliran air maka sistem akan mengirim SMS yang berisi notifikasi "Sistem aktif pompa tidak siap". Jika flowmeter membaca ada debet air saat pompa aktif, maka sistem akan mengirim SMS yang berisi notifikasi "Sistem aktif dan pompa siap" kemudian pompa kembali pada kondisi nonaktif.

3) Tahap selanjutnya sensor water level mendeteksi ketinggian air dalam tangki, jika S3 dalam kondisi 0 atau air dalam tangki dibawah batas minimum, maka pompa akan aktif.

4) Selama pompa aktif sensor flowmeter akan membaca debit air yang mengalir, pompa akan dinyatakan rusak apabila debet air yang terbaca dibawah debet minimum yang ditentukan.

5) Ketika pompa dinyatakan rusak, sistem akan otomatis menonaktifkan pompa dan mengirim SMS berisi notifikasi terjadi kerusakan, notifikasi kerusakan juga akan ditampilkan pada LCD. 
6) Jika debet air sesuai atau selalu diatas debet minimum selama pompa aktif, maka pompa akan mengisi tangki sampai S1 pada sensor water level berlogika 1 (air penuh), kemudian pompa otomatis akan nonaktif.

7) Sistem akan berhenti jika ada kerusakan yang terdeteksi.

\section{KESIMPULAN}

Setelah melakukan perancangan, dapat diambil kesimpulan sebagai berikut: 1) Perancangan prototipe pendeteksi kerusakan pompa air pada sistem pengisian air otomatis menggunakan flowmeter dan memanfaatkan SIMcom800L sebagai pemberi notifikasi berupa SMS telah sesuai dengan perencanaan dan tujuan dari penulisan. Dalam perancangan prototipe ini dilengkapi dengan LCD untuk menampilkan beberapa informasi saat sistem berjalan. 2) Prototipe ini menggunakan sensor flowmeter sebagai pendeteksi kerusakannya, berdasarkan pembacaan debet air minimum yang dapat ditentukan atau disesuaikan dengan kapasitas pompa yang akan digunakan.

\section{REFERENSI}

[1] Banzi, M. (2008). Getting Started With Arduino. USA: O'Reilly.

[2] Budiharto, W. (2008). Panduan Praktikum Mikrokontroler AVR Atmega 16. Jakarta: Gramedia.

[3] DFROBOT. (2017, Juni 29). I2C 20x4 Arduino LCD Display Module. Diambil kembali dari www.dfrobot.com: https://www.dfrobot.com/product590.html

[4] Hafni. (2012, agustus). proses pengolahan air bersih pada PDAM padang. 13, 1. Diambil kembali dari http://download.portalgaruda.org/articl e.php? article $=118792 \& \mathrm{val}=5448$

[5] KBBI Online. (2012). Arti kata merancang. Dipetik 7 11, 2017, dari Kamus Besar Bahasa Indonesia (KBBI): http://kbbi.web.id/rancang-2

[6] KBBI Online. (2012). Arti kata prototipe. (E. Setiawan, Produser, \& Badan Pengembangan dan Pembinaan Bahasa, Kemdikbud) Dipetik Juni 1, 2016, dari Kamus Besar Bahasa Indonesia (KBBI): http://kbbi.web.id/prototipe

[7] Nafisah, S. (2003). Pengertian Perancangan Sistem Berbagai Sumber. Dipetik 88 , 2017, dari ahlibaca.com: http://ahlibaca.com/pengertianperancangan-sistem-berbagai-sumber
[8] PERMENKES. (1990). PERMENKES Nomor 416 Tentang Syarat-syarat Dan Pengawasan Kualitas Air. Jakarta: Menteri Kesehatan Republik Indonesia. Diambil kembali dari http://docs.nazava.com/permenkes $\% 20$ 1990\%20air\%20bersih.pdf

[9] PERMENPU. (2006). PERMEN PU Nomor 29/PRT/M/2006 PEDOMAN PERSYARATAN TEKNIS BANGUNAN GEDUNG. Jakarta: MENTERI PEKERJAAN UMUM. Diambil kembali dari http://greenbuilding.jakarta.go.id/

[10] Prabowo, D., (2017) PERANCANGAN PROTOTIPE PENDETEKSI KERUSAKAN POMPA AIR PADA SISTEM PENGISIAN AIR OTOMATIS MENGGUNAKAN FLOWMETER DAN MEMANFAATKAN SIM800L SEBAGAI PEMBERI NOTIFIKASI SMS BERBASIS ARDUINO MEGA 2560, Makalah Komprehensif, Jakarta : Pendidikan T. Elektronika, Fakultas Teknik, Universitas Negeri Jakarta.

[11] Purnomo. (2011, Agustus 11). Mengenal Komunikasi I2C(Inter Integrated Circuit). Diambil kembali dari https://purnomosejati.wordpress.com/2 011/08/25/mengenal-komunikasii2cinter-integrated-circuit/

[12] seeedstudio. (2015, 6 4). G1/2 Water Flow sensor. Diambil kembali dari http://www.seeedstudio.com/wiki/G1/2 _Water_Flow_sensor

[13] setianto, J. e. (2014). Pengantar elektronika dan instrumentasi (pendekan project arduino dan android). yogyakarta: Andi Offset.

[14] SIMcom. (2013, 8 20). SIM800L_Hardware_Design_V1.00.

Diambil kembali dari wiki.seeedstudio.com:

http://wiki.seeedstudio.com/images/4/4 6/SIM800L_Hardware_Design_V1.00. pdf

[15] Siregar, K. T. (2013). Viskosimeter Digital Menggunakan Water Flow Sensor G1/2. 2. Diambil kembali dari https://jurnal.usu.ac.id/index.php/sfisik a/article/view/4754/2171

[16] Sugiyono. (2009). Metode Penelitian Pendidikan Pendekatan Kuantitatif, Kualitatif, dan $R \quad \& \quad D$. Bandung: Alfabeta. Diambil kembali dari https://pujiadilpmpjateng.wordpress.co $\mathrm{m} / 2014 / 03 /$ 
[17] Sugiyono. (2013). METODE PENELITIAN KUANTITATIF, KUALITATIF DAN $R \& D$. Bandung. Diambil kembali dari http://rayendar.blogspot.co.id/2015/06/ metode-penelitian-menurut-sugiyono2013.html

[18] Syahwil, M. (2013). Panduan Mudah Simulasi \& Praktek Mikrokontroler Arduino. Yogyakarta: CV Andi Offset.

[19] Yusro, M., dan Tim Doen FT UNJ. (2015). Buku Panduan Penyusunan Skripsi dan Non Skripi. Jakarta: FT UNJ 